\title{
An Intensive Family Intervention Clinic for Reducing Childhood Obesity
}

\author{
Ronit Endevelt, RD, MSc, PhD, Orit Elkayam, MD, Rinat Cohen, MD, \\ Ronit Peled, MPH, PhD, Limor Tal-Pony, BSc, RD, \\ Ruth Michaelis Grunwald, MHA, BSc, RD, Liora Valinsky, RN, BSc, MPH, \\ Avi Porath, MD, and Anthony David Heymann, MBBS
}

Background: Childhood and adolescent obesity constitute a significant public health concern. Family health care settings with multidisciplinary teams provide an opportunity for weight loss treatment. The objective of this study was to examine the effect of intensive treatment designed to reduce weight using a parent-child lifestyle modification intervention in a family health care clinic for obese and overweight children who had failed previous treatment attempts.

Methods: This was a practice-based 6-month intervention at Maccabi Health Care Services, an Israeli health maintenance organization, consisting of parental education, individual child consultation, and physical activity classes. We included in the intervention 100 obese or overweight children aged 5 to 14 years and their parents and 943 comparison children and their parents. Changes in body mass index $z$-scores, adjusted for socioeconomic status, were analyzed, with a follow-up at 14 months and a delayed follow-up at an average of 46.7 months.

Results: The mean $z$-score after the intervention was lower in the intervention group compared to the comparison group $(1.74$ and 1.95 , respectively; $P=.019)$. The intervention group sustained the reduction in $z$-score after an average of 46.7 months $(P<.001)$. Of the overweight or obese children, $13 \%$ became normal weight after the intervention, compared with $4 \%$ of the comparison children.

Conclusion: This multidisciplinary team treatment of children and their parents in family health care clinics positively affected measures of childhood obesity. Additional randomized trials are required to verify these findings. (J Am Board Fam Med 2014;27:321-328.)

Keywords: Childhood Obesity, Early Medical Intervention, Health Education

Childhood and adolescent obesity constitutes a significant public health concern. ${ }^{1}$ Both overweight and obesity, which are mainly caused by poor diet

This article was externally peer reviewed.

Submitted 27 August 2013; revised 22 December 2013; accepted 6 January 2014.

From Nutritional Services (RE, LT-P, RMG), Pediatric Gastroenterology and Nutrition Services, Maccabi Obesity Clinic (PE), the Pediatric Department (RC), Health Promotion and Preventive Medicine (LV), the Medical Division (AP), and Central Medical Management (ADH), Maccabi Healthcare Services, Tel Aviv, Israel; School of Public Health, University of Haifa, Haifa, Israel (RE); the Department of Health System Management, Faculty of Health Sciences, Ben Gurion University of the Negev, Beer Sheva, Israel (RP); and Sackler School of Medicine, University of Tel Aviv, Tel Aviv, Israel (ADH).

Funding: none.

Conflict of interest: none declared.

Corresponding author: Ronit Endevelt, RD, MSc, PhD, Nutrition and Nutritional Services, Maccabi Health Care Services, Hamered 27, Tel Aviv, Israel (E-mail: rendevelt@ univ.haifa.ac.il). and lifestyle in an obesogenic environment, ${ }^{2,3}$ have been shown to be risk factors for chronic morbidity in childhood and adulthood. ${ }^{4}$

The American Expert Committee recommendations regarding the prevention, assessment, and treatment of child and adolescent overweight, published in $2007,{ }^{5}$ endorsed several primary care practices, including (1) documenting body mass index (BMI) by the physician, with the opportunity to guide the family toward healthier behaviors; (2) establishing procedures to deliver obesity prevention messages to all children; and (3) involvement in and training of interdisciplinary teams, including nurses, physicians, and staff members.

Recent assessments point to the importance of improving children's environment and the time they spend engaged in physical activity. ${ }^{6}$ The primary care setting provides the opportunity for interventions to reduce childhood obesity, such as 
those successfully reported in the United Kingdom, the United States, and Singapore. ${ }^{7-10}$ There is moderate- to high-strength evidence that diet and/or physical activity interventions implemented in school settings help prevent weight gain or reduce the prevalence of overweight and obesity, as noted in a 2013 report from the American Agency for Health Research and Quality. ${ }^{11}$ The generalizability of evidence of the effectiveness of interventions primarily implemented in other settings is largely unknown. ${ }^{11}$

The role of parents in establishing a healthy home environment and supervising children's eating habits and lifestyle is crucial. Research shows a strong correlation between parental and child obesity, particularly among mothers and their children. ${ }^{12-14}$ Moreover, there is evidence of strong associations between parenting practices and children's eating habits, physical activity, and weight status, suggesting that the promotion of effective parenting is critical for the prevention of obesity. ${ }^{15-17}$

Maccabi Health Care Services (MHS) is the second largest health maintenance organization in Israel, providing primary care services to 2 million beneficiaries throughout the country. A recent MHS internal analysis revealed that $11.4 \%$ of boys and $12.2 \%$ of girls between the ages of 2 to 18 years treated by MHS were overweight, and $8.7 \%$ of the boys and $7.4 \%$ of the girls were obese according to BMI percentiles. These findings were the impetus for the development of an intensive parent-child intervention program.

Our hypothesis was that a parent-child treatment program in the family health care setting would result in significant child weight loss relative to usual childhood weight gain and that this relative loss can be sustained for a more than 2 years. This article presents the key elements of an intensive parent-child family care treatment program and examines the impact of this program on the relative weight loss of obese and overweight children.

\section{Methods \\ Setting}

Four MHS primary care clinics (combined family and pediatric care) were chosen to host a multidisciplinary team, which included a pediatrician, a dietician, a physical activity expert, and a social worker. These designated family clinics were oper- ated separately from the routine care normally provided, with a special space to conduct meetings and physical activities.

\section{Study Design}

This study was conducted as a practice-based community intervention. Children were recruited for the intervention between January 2006 and December 2007. The intervention program was operated in 6-month cycles.

\section{Inclusion Criteria}

From selected MHS regions we included children aged 5 to 14 years who were defined as overweight (according to Centers for Disease Control and Prevention BMI curves for the 85th to 94th percentiles) or as obese (according to Centers for Disease Control and Prevention BMI curves for the 95th percentile and above $)^{18}$ and who previously failed at least 2 other weight loss attempts (such as private consultation or self-effort to change lifestyle). Inclusion in the study required family physician referral and the willingness and commitment of the children and their parents to long-term participation in the intervention program. Both participants and their parents signed an informed consent and an agreement to take part in the program; the study was approved by the local ethics committee. The children were divided into 2 intervention groups: those 5 to 8 years old and those 9 to 14 years old.

The comparison group consisted of children aged 5 to 14 years, from the same MHS regions, who according to their computerized records were overweight or obese during the same time period and were matched (using a frequency matching method) to the intervention group by baseline BMI $z$ scores. Data for these children were gathered electronically.

\section{BMI Measurements}

The intervention lasted for 6 months and went in rounds. The children in the intervention group had their height and weight measured at 3 time points: (1) at enrollment in the program (baseline measurement); (2) after the intervention following a mean of 14.3 months (range, 12-18 months) from the baseline measurement (postintervention measurement); and (3) an additional measurement after a mean of 46.7 months (range, 36-67 months) from the baseline measurement (final measurement). For 
Table 1. Participants of Meetings Led by Dieticians and Social Workers

\begin{tabular}{|c|c|c|}
\hline Meeting & Subject & Participants \\
\hline 1 & $\begin{array}{l}\text { The meaning of a healthy lifestyle and the changes required in the environment } \\
\text { and behavior patterns, including shopping, exposure, choices, cooking, and } \\
\text { eating habits }\end{array}$ & Parents \\
\hline 2 & Promoting the motivation for a change & Parents \\
\hline 3 & $\begin{array}{l}\text { The meaning of an active lifestyle: changing the family's physical activity } \\
\text { patterns }\end{array}$ & Parents \\
\hline 4 & The parent as a role model & $\begin{array}{l}\text { Parents and children } \\
\text { role playing }\end{array}$ \\
\hline 5 & Parenting style and general parenthood skills & Parents \\
\hline 6 & Responsibility and boundaries in eating habits & Parents \\
\hline 7 & Strategies for dealing with conflicts and objections & Parents \\
\hline 8 & Family communication and adequate childhood body image & $\begin{array}{l}\text { Parents and children } \\
\text { role playing }\end{array}$ \\
\hline \multirow[t]{2}{*}{9} & Self-esteem promotion skills & Parents \\
\hline & Self- and body confidence & Children \\
\hline \multirow[t]{2}{*}{10} & $\begin{array}{l}\text { Food variety and introduction to nutrients; choosing appropriate high-value } \\
\text { foods }\end{array}$ & Parents \\
\hline & Healthy nutrition habits & Children \\
\hline 11 & How to spend leisure time; introduction to food labeling & Parents \\
\hline \multirow[t]{2}{*}{12} & Behavior skills at parties and social events & Parents \\
\hline & Dealing with tempting environment and developing resilience & Parents and children \\
\hline
\end{tabular}

the comparison group, the final measurement after the baseline (mean, 14.7 months) was used.

\section{Data Source}

Data were extracted for both study groups from the MHS central computer system, in which all the medical information, including BMI, is stored.

\section{The Intervention}

An intensive multidisciplinary parent-child intervention program was developed according to the theories of Golan and Crow. ${ }^{19,20}$ The program consisted of 3 elements.

1. Parents' education groups for nutrition and healthy behavior were held with a dietician and a social worker every 2 weeks for 6 months, for a total of 12 meetings. This part of the intervention aimed at providing parents with effective tools for modification of lifestyle and the family environment. Some of these group sessions were held jointly with the children to enhance family communication. The issues discussed during these group sessions included food-buying behavior, cooking habits and style, food choices, eating habits, physical and emotional morbidity related to overweight, parenting style and skills, family strategies for conflict resolution, and body image, among others (for more specific details of the program agenda see Table 1).

2. Children's individual therapy consisted of 6 individual meetings with a family physician, a physical therapist specializing in children's physical activity, and a dietician. This part of the intervention aimed at modifying nutrition and lifestyle; the physical therapist helped children incorporate physical activity into their routine. Sessions were provided separately for children aged 5 to 8 and 9 to 14 years; they had the same agenda but used an ageadjusted approach.

3. Physical activity groups for the children, with individual physical fitness monitoring, were conducted twice a week for 6 months. This program included setting individualized and tailored fitness goals, aerobic activities, and joint fun and leisure time physical activities for both children and parents.

Families paid NIS 1500 (approximately US\$450) per child for the 6-month program. MHS provided subsidies for children from low-income families.

\section{The Role of Each Profession in the Intervention}

The family physician evaluated each child's capability for physical activity, diagnosed obesity-related disease, and ordered blood tests as needed to 
detect other pathologies. The physician also provided the children and the parents with an explanation of the risks related to excessive weight. The dietician interviewed the parents and the children at enrollment, assessed the family's eating patterns, and helped each family to build a program for a healthier home environment tailored to their individual needs. In addition, the dietician monitored each child's BMI. The physical therapist diagnosed the children's musculoskeletal abnormalities related to obesity and helped each family plan how to increase the amount of physical activity in their weekly routine. The physical activity coach organized and facilitated the physical activity groups, often including activities tailored to specific children. The social worker, trained in psychosocial counseling, interviewed the parents to diagnose their parenting style and helped the parents in their efforts to promote a healthier family structure and increase parental authority when needed.

\section{Follow-up}

After the intervention, the children continued routine follow-up with their family physician. Routine follow-ups involved measuring and recording BMI. Children in the comparison group had routine follow-ups with their family physician and/or local dietician. They may have participated in privately run weight control programs that were open to the public during the same period of time, but their participation was not tracked.

\section{Statistical Analysis}

Only children (and their families) from the intervention group who had participated in at least $85 \%$ of the meetings, including the physical activity classes, were included in the analysis. A $z$ score (population norms) by age and sex was calculated for each BMI measurement ${ }^{21}$ using SPSS 19 software (SPSS, Inc., Chicago, IL).

Univariate analysis techniques were used to evaluate the differences between the groups for baseline and postintervention BMI $z$ scores, age, sex, socioeconomic rank (SER), and weight category. According to the nature of the variables either $t$ test or $\chi^{2}$ analyses were used. As previously mentioned, an additional measurement was performed for the intervention group after an average of 46.7 months from the baseline (final measurement). For this group only, paired $t$ tests were used to analyze the differences in BMI $z$ scores from baseline to the last measurement.

The SER ranks as recorded on the MHS database were used for each child in accordance with Israeli Census data, ${ }^{22}$ which provide 20 categories ranging from 1 (very low) to 20 (very high). The 20 categories were collapsed into 4 ranks $(1-5,6-10$, 11-15, and 16-20). For the multivariate analysis, linear regression models were estimated for the change in BMI $z$ score (postintervention minus baseline), which was the dependent variable. The independent variables entered into the final model were group (intervention $=1$; comparison $=0$ ) and SER.

\section{Results}

We recruited 116 children for the intervention; 16 children and their families who did not complete the full term of the intervention were excluded from the analysis. Thus, the intervention group consisted of 100 children, including 63 girls and 37 boys, and their parents. The comparison group comprised 943 children, with $43.7 \%$ girls and $56.3 \%$ boys $(P<.001)$ (Figure 1$)$. A significant difference was found in the SER between the 2 groups (Table 2).

The average time between the baseline and postintervention measurements was 14.3 (standard deviation $[\mathrm{SD}], \pm 1.5)$ and $14.7(\mathrm{SD}, \pm 1.7)$ months for the intervention and comparison groups, respectively $(P=.038)$. The average time from the baseline to the last measurement (intervention group only) was 46.7 months (SD, \pm 12.4 months). The mean $z$ scores at baseline were not significantly different between the 2 groups $(P<.099)$ (Table 3). The mean $z$ score for the postintervention measurement was lower in the intervention group than in the comparison group $(P=.019)$ (Table 3).

At recruitment, the rates of overweight and obesity were almost the same. However, the rate of obesity decreased by $55 \%$ in the intervention group compared with $11 \%$ in the comparison group ( $\mathrm{Ta}$ ble 3). Multivariate analysis revealed that after controlling for SER, the intervention was found to have a positive effect on the change between the baseline and the postintervention BMI $z$ scores, with a more significant effect for obese children than for children who were overweight at baseline (Table 4). 
Figure 1. Flow chart of the study population.

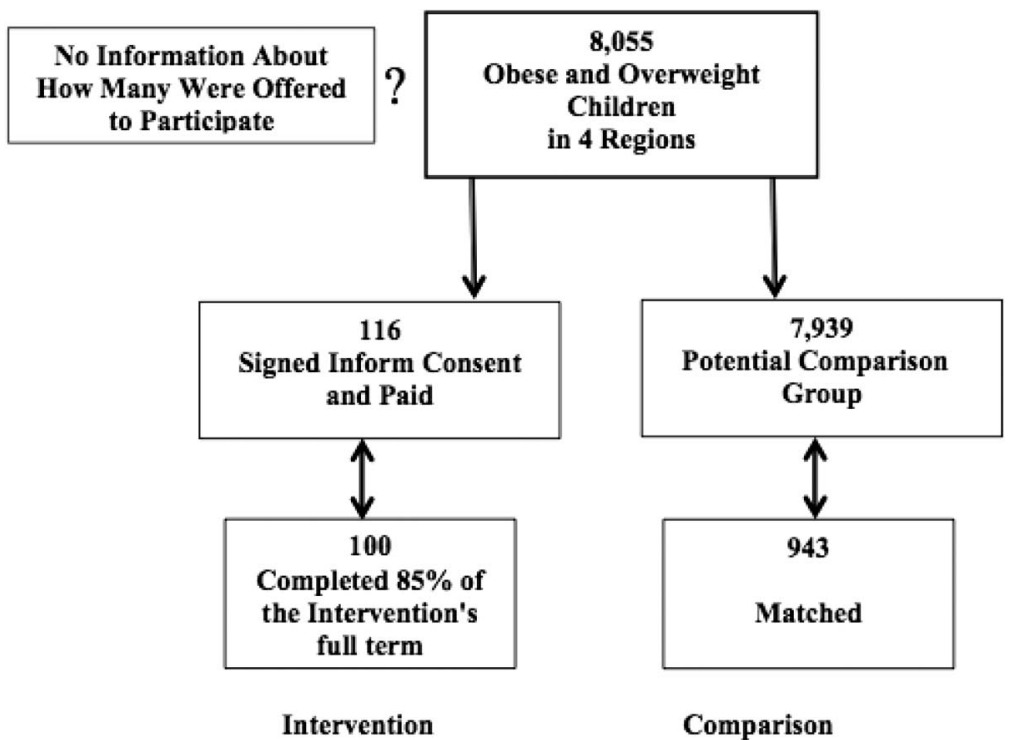

\section{Discussion}

The study results suggest that an intensive parentchild treatment program, conducted in designated family health care clinics by a multidisciplinary team, was associated with lower increase in children's weight compared with comparison children and that this difference was sustained over more than 2 years. Moreover, the association between the intervention and the reduction in weight was more robust for children who were obese than those who were overweight at baseline. These findings are possible because the parents of obese children are likely more aware of their child's condition and that underestimation of the overweight children's condition might impair parents' motivation to adopt weight control measures. ${ }^{23,24}$

\section{Table 2. Descriptive Characteristics of Study Groups}

\begin{tabular}{lccr}
\hline & $\begin{array}{c}\text { Intervention } \\
\text { Group } \\
(\mathrm{n}=100)\end{array}$ & $\begin{array}{c}\text { Comparison } \\
\text { Group } \\
(\mathrm{n}=943)\end{array}$ & $\begin{array}{c}P \\
\text { Value }\end{array}$ \\
\hline $\begin{array}{l}\text { Mean age } \pm \text { SD at } \\
\text { recruitment, years }\end{array}$ & $9.03 \pm 1.6$ & $9.0 \pm 2.7$ & .912 \\
Girls (\%) & 63.0 & 43.7 & $<.001$ \\
Socioeconomic rank (\%) & & & \\
$1-5$ & 3.4 & 9.3 & $<.001$ \\
$6-10$ & 12.4 & 28.3 & \\
$11-15$ & 42.7 & 38.7 & \\
$16-20$ & 41.6 & 33.7 & \\
\hline
\end{tabular}

SD, standard deviation.
The decision to initiate the intensive care clinics, designated solely for nutrition behavior and lifestyle modification, was based on the urgent need to address the prevention, identification, and treatment of childhood obesity and overweight problems ${ }^{25,26}$ and on the success of such clinics in other countries. The program combined most of the elements that have been suggested as key to the

Table 3. Z-scores and Weight Categories by Study Groups

\begin{tabular}{lccr}
\hline Variable & $\begin{array}{c}\text { Intervention } \\
\text { Group }\end{array}$ & $\begin{array}{c}\text { Comparison } \\
\text { Group }\end{array}$ & $\begin{array}{c}P \\
\text { Value }\end{array}$ \\
\hline $\begin{array}{l}\text { Mean } z \text {-score } \pm \mathrm{SD} \\
\text { At baseline } \\
\quad \text { measurement }\end{array}$ & $2.07 \pm 0.35$ & $2.12 \pm 0.3$ & .099 \\
After the intervention & $1.74 \pm 0.8$ & $1.95 \pm 0.4$ & .019 \\
$\quad$ At last measurement & $1.75 \pm 0.6$ & - & $<.000^{*}$ \\
$\begin{array}{l}\text { Weight categories at } \\
\text { baseline (\%) }\end{array}$ & & & \\
$\begin{array}{l}\text { Overweight } \\
\text { Obesity }\end{array}$ & 25.0 & 29.6 & .337 \\
$\begin{array}{l}\text { Weight categories after } \\
\text { intervention }\end{array}{ }^{\dagger}$ (\%) & 75.0 & 70.4 & \\
$\begin{array}{l}\text { Normal } \\
\text { Overweight }\end{array}$ & 13.0 & & \\
Obesity & 53.0 & 32.9 & \\
\hline
\end{tabular}

*Paired $t$ test, baseline measurement vs. last measurement (average of 46.7 months from baseline).

${ }^{\dagger}$ Next measurement after the intervention ended; $z$-score controls for age and sex.

$\mathrm{SD}$, standard deviation. 
Table 4. Linear Regression Analysis Results for the Dependent Variable $\Delta \mathrm{Z}$ Score (After Intervention - Baseline Measurements)

\begin{tabular}{lrcc}
\hline Model & $\mathrm{B}^{*}$ & $\begin{array}{c}\text { Standard } \\
\text { Error }\end{array}$ & $\begin{array}{c}P \\
\text { Value }\end{array}$ \\
\hline $\begin{array}{l}\text { Model 1: all children } \\
\quad \text { Intervention }\end{array}$ & -0.118 & 0.049 & .016 \\
$\quad$ SER & 0.046 & 0.016 & .004 \\
Model 2: obese children & & & \\
$\quad$ Intervention & -0.112 & 0.056 & .047 \\
$\quad$ SER & -0.059 & 0.019 & .02 \\
Model 3: overweight children & & & \\
$\quad$ Intervention & -0.128 & 0.099 & .195 \\
$\quad$ SER & -0.014 & 0.029 & .621 \\
\hline
\end{tabular}

${ }^{*}$ Model coefficient.

SER, socioeconomic rank.

success of an intervention with overweight children, including parental involvement in treatment, ${ }^{19,20,27}$ behavioral modification, and the intensity of physical activity and the intervention. ${ }^{28}$ As such, the children participated in twice weekly physical activity sessions, classes about eating and lifestyle habits, and cooking workshops, while the parents participated in workshops guided by a dietician and a social worker to help modify their parenting style. The participation and involvement of parents in any childhood obesity treatment is crucial. ${ }^{19,29-31}$ Both mothers and fathers ${ }^{32}$ influence their children's eating habits through the control of food socialization practices and through their food-related parenting style. The home environment is thus a critical sociocultural component in the development of eating disorders. ${ }^{24}$ Therefore, successful treatment should be family-based and should incorporate physical, nutritional, and psychological components. ${ }^{31,32-35}$ This family-based intervention approach can be implemented through designated clinics or other community centers in developed as well as developing countries suffering from the growing epidemic of childhood obesity.

One of our important results was the sustainability of the intervention's impact. Only a few studies $^{36-40}$ have reported follow-up measures after an intervention (from 5 to 12 months) with positive outcomes in either behavioral or anthropometric measures.

As was recently published, ${ }^{33}$ both parents and children reported the need for ongoing support to sustain the behavioral changes made during treat- ment. Therefore, from the very beginning it was understood that the intervention must incorporate strategies for healthier home environments that promote autonomy and self-regulation. These strategies are critical for building a family's confidence in their ability to sustain their newly acquired health behaviors independent of health professionals' support. In addition, we decided to conduct the intervention activities for 6 months, a period that was considered to be sufficient for ensuring sustained behavioral change. The results confirm this preliminary assumption and show that the intervention effect was sustained for almost 4 years.

Researchers from Germany recently found that a certain set of family characteristics might predict the success of a long-term weight reduction program, with the need for tailored interventions. ${ }^{41}$ Likewise, our participants were recruited selectively; the strategy was to recruit families who were able to commit to a 6-month program on a biweekly basis and to the follow-up provided by routine pediatric care after the program ended. It is believed that this element further contributed to the success of the intervention program.

The comparison group also demonstrated a decrease in BMI ( $z$ score), albeit less so than the intervention group. This may be explained by other external factors, such as increasing public awareness about the risks of childhood obesity, consultation received from primary care physicians, and participation in other private programs with no documentation.

\section{Study Limitations}

One limitation of this study was its lack of randomization, which prohibits a presentation of causal inferences. The children and their families were recruited for the intervention based on their failure in routine and other treatments, their commitment to long-term participation, and their willingness to pay for the services rendered. The comparison group was gathered from the same clinics. Our method resulted in more girls and higher socioeconomic status in the treatment group despite providing subsidies. Yet for these types of interventions, randomized recruitment is often difficult, as previously described. ${ }^{42,43}$ Furthermore, although there was potential selection bias, our results highlight the potential advantages of this kind of intensive treatment for reducing children's relative weight and fighting obesity. 
Controlling for the willingness to change behavior and habits was not feasible; however, the study controlled for age and sex (by calculating $z$ scores) and for socioeconomic status in multivariate analysis. The postintervention measurements were taken 14 months after initiation and were timed as such to occur after all groups completed the full program. This might be a limitation because we do not know what happened to the children's weight immediately after the intervention. ${ }^{44}$ The database lacked any process measurements or information about the changes in waist circumference. However, it is known that children's waist circumference and BMI are well correlated. ${ }^{45}$

Another limitation of the program was its high cost. Families paid NIS 1,500 (US\$450), which can be considered quite expensive for a health treatment that is normally free in Israel. However, the cost should not be viewed as a cause for bias because MHS subsidized the study for children whose families could not afford the costs associated with the intervention. Moreover, we controlled for SER in the multivariate modeling.

A limitation regarding the comparison group was the lack of specific information about the extent to which they may have participated in other weight control programs. Also, no information about their BMI was available after more than 14 months.

\section{Conclusion}

An intensive multidisciplinary parent-child treatment program at designated family overweight and obesity primary care clinics was associated with relative weight loss among children (by BMI $z$ score), which was sustained for a long period of time. Further research using randomized techniques and intervention and control groups is recommended.

\section{References}

1. Olds T, Maher C, Zumin S, et al. Evidence that the prevalence of childhood overweight is plateauing: data from nine countries. Int J Pediatr Obes 2011;6: 342-60.

2. Nicklas TA, Morales M, Linares A, et al. Children's meal patterns have changed over a 21-year period: the Bogalusa Heart Study. J Am Diet Assoc 2004; 104:753-61.

3. O'Connor A. Promoting healthy eating and an active lifestyle in schoolchildren. Nurs Stand 2011;25:48-56.

4. Bishop J, Middendorf J, Babin T, Tilson W. ASPE research brief. Childhood obesity. Washington, DC: U.S. Department of Health \& Human Services;
2005. Available from: http://aspe.hhs.gov/health/ reports/child_obesity. Accessed December 2012.

5. Barlow SE; Expert Committee. Expert committee recommendations regarding the prevention, assessment, and treatment of child and adolescent overweight and obesity: summary report. Pediatrics. 2007;120(Suppl 4):S164-92.

6. Larson N, Ward DS, Neelon SB, Story M. What role can child-care settings play in obesity prevention? A review of the evidence and call for research efforts. J Am Diet Assoc 2011;111:1343-62.

7. Banks J, Sharp DJ, Hunt LP, Shield JP. Evaluating the transferability of a hospital-based childhood obesity clinic to primary care: a randomized controlled trial. Br J Gen Pract 2012;62:e6-12.

8. Rattay KT, Ramakrishnan M, Atkinson A, Gilson M, Drayton $\mathrm{V}$. Use of an electronic medical record system to support primary care recommendations to prevent, identify, and manage childhood obesity. Pediatrics 2009;123(Suppl 2):S100-7.

9. Ray R, Lim LH, Ling SL. Obesity in preschool children: an intervention programme in primary health care in Singapore. Ann Acad Med Singapore 1994;23:335-41.

10. Siwik V, Kutob R, Ritenbaugh C, et al. Intervention in overweight children improves body mass index (BMI) and physical activity. J Am Board Fam Med 2013;26:126-37.

11. Childhood obesity prevention programs: comparative effectiveness review and meta-analysis. Executive summary. Comparative effectiveness review no. 115. AHRQ pub. no. 13-EHC081-1-EF. Rockville, MD: Agency for Healthcare Research and Quality; 2013. Available from: http://effectivehealthcare.ahrq. gov/ehc/products/330/1523/obesity-child-executive130610.pdf. Accessed March 6, 2014.

12. Faith MS, Heshka S, Keller KL, et al. Maternalchild feeding patterns and child body weight: findings from a population- based sample. Arch Pediatr Adolesc Med 2003;157:926-32.

13. Dubois L, Girard M. Early determinants of overweight at 4.5 years in a population-based longitudinal study. Int J Obes (Lond) 2006;30:610-7.

14. Jääskeläinen A, Pussinen J, Nuutinen O, et al. Intergenerational transmission of overweight among Finnish adolescents and their parents: a 16-year follow-up study. Int J Obes (Lond) 2011;35:1289-94.

15. Stang J, Loth KA. Parenting style and child feeding practices: potential mitigating factors in the etiology of childhood obesity. J Am Diet Assoc 2011;111: 1301-5.

16. Ventura AK, Birch LL. Does parenting affect children's eating and weight status? Int J Behav Nutr Phys Act 2008;5:15.

17. Rhee K. Childhood overweight and the relationship between parent behaviors, parenting style, and family functioning. Ann Am Acad Pol Soc Sci 2008;615: 11-37. 
18. Overweight and obesity. Basics about childhood obesity. Atlanta: Centers fro Disease Control and Prevention; 2012. Available from: http://www.cdc. gov/obesity/childhood/basics.html. Accessed April 2013.

19. Golan M. Parents as agents of change in childhood obesity-from research to practice. Int J Pediatr Obes 2006; 1:66-76.

20. Golan M, Crow S. Parents are key players in the prevention and treatment of weight-related problems. Nutr Rev 2004;62:39-50.

21. Growth charts. Z-score data files. Atlanta: Centers fro Disease Control and Prevention; 2009. Available from: http://www.cdc.gov/growthcharts/zscore.htm. Accessed March 2014.

22. Central Bureau of Statistics. [in Hebrew]. Available from: http://www1.cbs.gov.il/census/census/text_ search_census_enew.html? input $=\%$ e $0 \%$ f $9 . \%$ eb $\%$ e5\% ec\&search_kind=3. Accessed March 2014.

23. Vuorela N, Saha MT, Salo MK. Parents underestimate their child's overweight. Acta Paediatr 2010;99:1374-9.

24. Vanhala ML, Keinänen-Kiukaanniemi SM, Kaikkonen KM, Laitinen JH, Korpelainen RI. Factors associated with parental recognition of a child's overweight status-a cross sectional study. BMC Public Health 2011;11:665.

25. Haemer M, Cluett S, Hassink SG, et al. Building capacity for childhood obesity prevention and treatment in the medical community: call to action. Pediatrics 2011;128(Suppl 2):S71-7.

26. Krebs NF, Jacobsen MS; American Academy of Pediatrics Committee on Nutrition. Prevention of pediatric overweight and obesity. Pediatrics. 2003;112:424-30.

27. Yackobovitch-Gavan M, Nagelberg N, Phillip M, Ashkenazi-Hoffnung L, Hershkovitz E, Shalitin S. The influence of diet and/or exercise and parental compliance on health-related quality of life in obese children. Nutr Res 2009;29:397-404.

28. Whitlock EP, O'Conner EA, Williams SB, Beil TL, Lutz KW. Effectiveness of primary care interventions for weight management in children and adolescents: an updated, targeted systematic review for the USPSTF. Report no. 10-05144-EF-1. Rockville, MD: Agency for Healthcare Research and Quality; 2010. Available from: http://www.ncbi.nlm.nih.gov/ books/NBK36416/. Accessed December 2012.

29. French SA, Story M, Jeffery RW. Environmental influences on eating and physical activity. Annu Rev Public Health 2001;22:309-35.

30. Stokols D. Translating social ecological theory into guidelines for community health promotion. Am J Health Promot 1994;10:282-98.

31. Lent M, Hill TF, Dollahite JS, Wolfe WS, Dickin KL. Healthy children, healthy families: parents making a difference! A curriculum integrating key nutrition, physical activity, and parenting practices to help prevent childhood obesity. J Nutr Educ Behav. 2012;44:90-2.
32. Enten RS, Golan M. Parenting styles and eating disorder pathology. Appetite 2009;52:784-7.

33. Staniford LJ, Breckon JD, Copeland RJ, Hutchison A. Key stakeholders' perspectives towards childhood obesity treatment: a qualitative study. J Child Health Care 2011;15:230-44.

34. Collaboration for Health, Activity, and Nutrition in Children's Environments (CHANCE). Ithaca, NY: Cornell University Division of Nutritional Sciences; 2009. Available from: http://www.fnec.cornell.edu/Our Initiatives/CHANCE.cfm. Accessed December 2012.

35. Lent M, Dollahite JS, Dickin KL, Hill TF. Collaboration for Health, Activity, and Nutrition in Children's Environments (CHANCE): helping low-income parents prevent childhood overweight. J Nutr Educ 2009;41(Suppl 1):S36-7.

36. Epstein LH, Paluch RA, Raynor HA. Sex differences in obese children and siblings in family-based obesity treatment. Obes Res 2001;9:746-53.

37. Epstein LH, Valoski AM, Vara LS, et al. Effects of decreasing sedentary behavior and increasing activity on weight change in obese children. Health Psychol 1995;14:109-15.

38. Escobar-Chaves SL, Markham CM, Addy RC, Greisinger A, Murray NG, Brehm B. The Fun Families study: intervention to reduce children's TV viewing. Obesity 2010;18:S99-101.

39. Slootmaker SM, Chinapaw MJM, Seidell JC, van Mechelen W, Schuit AJ. Accelerometers and Internet for physical activity promotion in youth? Feasibility and effectiveness of a minimal intervention. Prev Med 2010;51:31-6.

40. Salmon J, Ball K, Hume C, Booth M, Crawford D. Outcomes of a group- randomized trial to prevent excess weight gain, reduce screen behaviors and promote physical activity in 10-year-old children: Switch-Play. Int J Obes 2008;32:601-12.

41. Fröhlich G, Pott W, Albayrak Ö, Hebebrand J, Pauli-Pott U. Conditions of long-term success in a lifestyle intervention for overweight and obese youths. Pediatrics 2011;128:e779-85.

42. McCallum Z, Wake M, Gerner B, et al. Outcome data from the LEAP trial: a randomized controlled trial of a primary care intervention for childhood overweight/mild obesity. Int J Obes. 2007;31:630-6.

43. Taveras EM, Gortmaker SL, Hohman KH, et al. Randomized controlled trial to improve primary care to prevent and manage childhood obesity. Arch Pediatr Adolesc Med 2011;165:714-22.

44. Magarey AM, Perry RA, Baur LA, et al. A parent-led family-focused treatment program for overweight children aged 5 to 9 years: the PEACH RCT. Pediatrics 2011;127:214-22.

45. Bigornia SJ, Lavalley MP, Benfield LL, Ness AR, Newby PK. Relationships between direct and indirect measures of central and total adiposity in children: what are we measuring? Obesity (Silver Spring) 2013; 21:2055-62. 